\title{
NGHIÊN CÚU ĐỊNH LƯợNG VI NHỰA TRONG CÁC SẢN PHẨM CHĂM SÓC CÁ NHÂN BĂNG PHHƯONG PHÁP NHUỌMM NILE RED VÀ KHẢO SÁT SỰ HIỂU BIẾT CỦA NGƯờI TIÊU DÙNG VỀ TỒN TẠI VI NHỤ̉A TRONG CÁC SẢN PHẨM NÀY
}

\author{
LÊ HÙNG ANH, NGUYỄN THI THANH TRÚC, NGUYỄN THI NGỌC SANG \\ Viện Khoa học Công nghệ và Quản lý Môi truờng, Đại học Công nghiệp Thành phố Hồ Chí Minh \\ nguyenthithanhtruc_vmt@iuh.edu.vn
}

Tóm tắt: Vi nhựa có trong các sản phẩm chăm sóc cá nhân được xác định là một trong những nguồn gây ô nhiễm nhựa trong môi trường biển. Tuy nhiên, việc nghiên cứu còn khá hạn chế tại Việt Nam. Nghiên cứu này phát triển phương pháp nhuộm huỳnh quang Nile Red nhằm xác định sự có mặt của vi nhựa trong các sản phẩm kem đánh răng và sản phẩm tẩy tế bào chết có nguồn gốc trong và ngoài nước. Kết quả cho thấy có hai sản phẩm tẩy tế bào chết chứa vi nhựa có kích thước nhỏ hơn $5 \mathrm{~mm}$ với mật độ cao nhất là mẫu C1 trong khoảng 2677 hạt/1g sản phẩm. 15 trên 24 mẫu sản phẩm kem đánh răng tồn tại vi nhựa có kích thước nhỏ hơn $1 \mathrm{~mm}$ với mật độ cao nhất là mẫu R1 17.582 hạt/1g sản phẩm. Nghiên cứu cũng tiến hành khảo sát hơn 100 người cho thấy sự hiểu biết của họ đối với sự hiện diện của MPs trong các sản phẩm chăm sóc cá nhân còn rất thấp, chỉ $28,5 \%$ số người khảo sát biết rõ và quan tâm đến vấn đề. Tuy nhiên, có đến $84 \%$ số người được khảo sát quyết định ngừng sử dụng và sẵn sàng khuyến cáo cho người thân, bạn bè đối với các sản phẩm có chứa MPs.

Từ khoá: Microplastics, Vi nhựa, Nile Red, Kính hiển vi huỳnh quang, Mỹ phẩm, Microbead

\section{QUANTIFICATION OF MICROPLASTICS IN PERSONAL CARE PRODUCTS USING NILE RED STAINING METHOD AND CONSUMER SURVEY OF UNDERSTANDING MICROPLASTIC EXISTENCE IN THESE PRODUCTS}

\begin{abstract}
Microplastics found in personal care products and cosmetics have been assessed as one of the sources of plastic pollution in marine environments. However, microplastic research is quite limited in Vietnam. This study developed a Nile Red staining method to determine the microplastic presence in personal care products with domestic and foreign origin. Using fluorescence microscopy shows the presence of microplastic particles in toothpaste and exfoliating cosmetic samples. Both of exfoliating products were determined the microplastic existence with a size less than $5 \mathrm{~mm}$. The $\mathrm{C} 1$ sample has the highest density of 2677 particles/ 1g of the product. 15 of 24 toothpaste samples exist microplastic with a size less than $1 \mathrm{~mm}$. In there, the highest density is the R1 sample with 17.582 particles/ $1 \mathrm{~g}$ product. The study also conducted a survey of more than 100 people that showed the surveyed people's comprehension about the MPs presence in personal care products was very low, only $28.5 \%$ of the surveyed people know and care to the problem. However, up to $84 \%$ of people surveyed decided to stop using and are willing to recommend to relatives and friends for products containing MPs.
\end{abstract}

Keyword: Microplastic, Microbead, cosmetics, Nile Red, Fluorescence microscopy lab

\section{TỔNG QUAN}

Microplastics - MP (vi nhựa) là những mảnh nhựa nhỏ có kích thước $<5 \mathrm{~mm}$. Trong đó, vi nhựa lớn có kích thước từ $1 \mathrm{~mm}-5 \mathrm{~mm}$ (nhìn thấy được), vi nhựa nhỏ có kích thước từ $20 \mu \mathrm{m}-1 \mathrm{~mm}$ [1]. Vi nhựa thông thường được tạo thành từ các nhựa cơ bản như polypropylen $(\mathrm{PP})$, polyetylen terephthalate (PET), polymethyl methacrylate (PMMA), nylon và polyetylen (PE) qua quá trình bào mòn tự nhiên hoặc phân mảnh bằng cơ học. Do vậy, hình dạng của vi nhựa từ quá trình này rất đa dạng, bao gồm dạng hạt, dạng tấm mỏng, dạng mảnh nhỏ, dạng sợi và được gọi là vi nhựa thứ cấp [2]. Bên cạnh đó, một số loại hạt nhựa (hạt nhựa sơ cấp) được sản xuất và dùng trực tiếp trong các sản phẩm với các mục đích khác nhau nhưtrong mỹ phẩm và mài mòn công nghiêp, in $3 \mathrm{D}$, đồ chơi trẻ em [3]. Vi nhựa sơ cấp có trong các sản phẩm chăm sóc cá nhân và mỹ phẩm với mục đích để tăng khả năng làm sạch và tẩy rửa . Một số báo cáo cho thấy việc 


\section{TỒN TẠI VI NHỰA TRONG CÁC SẢN PHẨM NÀY}

sử dụng MP để thay thế các nguyên liệu tẩy rửa tự nhiên (đá bọt, bột yến mạch, quả mơ hoặc vỏ quả óc chó) trong một loạt các sản phẩm như làm sạch tay, xà phòng, kem đánh răng, bọt cạo râu, sữa tắm, kem chống nắng, dầu gội đầu và tẩy tế bào chết trên mặt và cơ thể [4], [5].

Ngành công nghiệp mỹ phẩm sử dụng thuật ngữ "microbead, microspheres, nanospheres" để mô tả hạt nhựa có kích thước thước < $1 \mathrm{~mm}$ trong các sản phẩm làm đẹp. [5]. Có khoảng $93 \%$ trong số microbead được sử dụng trong mỹ phẩm là $\mathrm{PE}, \mathrm{PP}, \mathrm{PET}, \mathrm{PMMA}$ và nylon [6], [5], [7]. Theo uớc tính, khoảng 4360 tấn vi nhựa được sử dụng trong việc sản xuất các sản phẩm chăm sóc sản phẩm cá nhân và mỹ phẩm ở các nước Liên minh Châu Âu, Na Uy và Thụy Sĩ mỗi năm [6]. Sau quá trình sử dụng các sản phẩm này, microbead sẽ được thải ra trung bình khoảng $2,4 \mathrm{mg} \mathrm{MP} \mathrm{/} \mathrm{người} \mathrm{/} \mathrm{ngày} \mathrm{[8]} \mathrm{bằng} \mathrm{với} \mathrm{mức} \mathrm{trung} \mathrm{bình} \mathrm{là} 212$ $\mathrm{g} /$ năm / đầu người, tương ứng với 1,53 triệu tấn / năm của các hạt nhựa sơ cấp được sử dụng [9]. Các hạt vi nhựa này sẽ xâm nhập vào môi trường tự nhiên hoặc đi vào hệ thống xử lý nước thải tập trưng. Ở đây, một số hạt nhựa sẽ được giữ lại trong quá trình oxy hóa hoặc bùn thải. Tuy nhiên, do kích thước nhỏ nên một tỷ lệ đáng kể các vi nhựa này sẽ đi qua các hệ thống lọc và xâm nhập vào môi trường nước [4]. Khoảng 4594 - 94.500 hạt vi nhựa được giải phóng vào môi trường từ việc sử dụng các sản phẩm tẩy da chết có thể ảnh hưởng trực tiếp nghiêm trọng đến môi trường [10]. Theo nghiên cứu của $\mathrm{M}$. Eriksen và cộng sụ, có hơn 5 nghìn tỷ mảnh nhựa đang trôi nổi trên biển, trong đó vi nhựa chiếm hơn $94 \%$ [11]. Những phát hiện chỉ ra rằng có thể các hạt vi nhựa phát thải từ các sản phẩm chăm sóc cá nhân và mỹ phẩm có thể làm ô nhiễm nghiêm trọng môi trường nước sông và môi trường biển. Vi nhựa trôi nổi này dễ bị các sinh vật biển như cá, nghêu, sò, mực ăn phải và tồn tại trong cơ thể chúng. Cuối cùng, vi nhựa lại được đưa vào cơ thể con người khi ăn phải các sinh vật biển này. Tuỳ thuộc vào kích thước, hình dạng và thành phần hoá học, vi nhựa làm cản trở quá trình tiêu hoá, có thể đi vào trong các mô nhỏ tế bào ảnh hưởng đến trao đổi chất của cơ thể. Microplastic có thể hoạt động như vectơ vận chuyển các chất ô nhiễm trong nước và có tiềm năng hấp phụ một loạt các chất ô nhiễm hóa học kỵ nước [12]. Một số chất độc như phthalates, bisphenol A và các chất ô nhiễm vô cơ cũng dễ dàng hấp phụ lên vi nhựa và ảnh hưởng bất lợi đến sức khoẻ cũng như gia tăng nguy cơ ung thư [13]. Hơn nữa sự phân rã của các vi nhựa thông qua các quá trình hóa học, vật lý và sinh học có thể sẽ dẫn đến sự hình thành nanoplastic. Bản chất kỵ nước của các hạt nanoplastic sẽ dễ dàng thâm nhập vào các tế bào, dẫn đến gây độc tính tế bào [14]. Vì vậy, việc xác định vi nhựa, ngăn ngừa, hạn chế sự phát tán và loại bỏ chúng khỏi môi trường là thách thức hiện nay.

Việc đánh giá thành phần vi nhựa thông qua quang phổ chuyển đổi hồng ngoại Fourier (FT-IR), quang phổ Raman(Raman spectroscopy) và sắc ký khí (Pyrolysis-gaschromatography) là những phương pháp thường được áp dụng phổ biến hiện nay. Tuy nhiên, các phương pháp này tốn kém do chi phí thiết bị và vận hành cao, đồng thời, quá trình phân tích cần có yêu cầu chuyên môn. Phương pháp nhuộm huỳnh quang bằng thuốc nhuộm Nile Red là lần đầu tiên được sử dụng trong lĩnh vực vi sinh dùng để định tính lipid trên tể bào vi tảo [15]. Hiện nay, trong một số thử nghiệm phân biệt các hạt nhựa trong hỗn hợp chứa nhiều hạt cát, phương pháp nhuộm nile red là lựa chọn tổi ưu trong việc xác định và định lượng hạt $\mathrm{PP}$ cách đơn giản và nhanh chóng.

\section{VẠT LIỆU VÀ PHƯƠNG PHÁP NGHIÊN CỨU}

\subsection{Vật liệu và thiết bị}

Hai loại mỹ phẩm tẩy tế bào chết (MPT) được ký hiệu $\mathrm{C} 1$ và $\mathrm{C} 2$ và 24 loại kem đánh răng (KĐR) ký hiệu R1- R24 sử dụng trong nghiên cứu này bao gồm KĐR trẻ em (4 mẫu), KĐR cho người lớn (16 mẫu) và mẫu KĐR trong khách sạn (4 mẫu). Do tên thương hiệu không là mục đích của nghiên cứu này nên bài báo sử dụng các ký hiệu trên để phân biệt đối tượng mẫu. Các mẫu MPT và KĐR từ các thương hiệu ngoại nhập lẫn nội địa được mua ở chợ và siêu thị trên địa bàn Tp. Hồ Chí Minh.

Mẫu nhựa chuẩn sử dụng để đối chiếu bao gồm HDPE (High-density polyethylene), LDPE (low-density polyethylene), PP (Polypropylen) và PET (Polyethylene terephthalate) được cung cấp từ Công ty TNHH Cơ khí nhựa Việt Úc.

Các thí nghiệm xác định vi nhựa trong sản phẩm chăm sóc cá nhân sử dụng giấy lọc Cellulose Nitrate có kích thước lỗ lọc $0,45 \mu \mathrm{m}$ (Whatman, Anh). Thuốc nhuộm huỳnh quang Nile Red (9-diethylamino-5Hbenzo $[\alpha]$ phenoxazine-5-one, Sigma, Đức) sử dụng để nhuộm màu mẫu sản phẩm sau quá trình chiết lọc. Dung dịch acetone (Merk, Đức) dùng làm dung môi pha loãng Nile Red. Quá trình chiết lọc vi nhựa từ các sản phẩm chăm sóc cá nhân sử dụng nước cất 2 lần. Máy lắc tròn $\mathrm{SM} 30 \mathrm{~A}$ (Edmund Buhler, Đức) dùng để 
đảo trộn dung dịch giúp cho thuốc nhuộm tiếp xúc đến các vi nhựa có trong dung dịch mẫu. Quá trình chiết lọc mẫu được thực hiện bằng máy lọc chân không (JOAN LAB, Đài Loan). Kính hiển vi huỳnh quang Olympus BX 53 (Nhật Bản) được sử dụng để quan sát mẫu và một máy chụp hình Olympus DP 73 (Nhật Bản) được gắn vào kính hiển vi nhằm lưu lại các hình ảnh về mẫu vi nhựa.

\subsection{Phương pháp nhuộm Nile Red và xác định vi nhựa bằng kính hiển vi huỳnh quang}

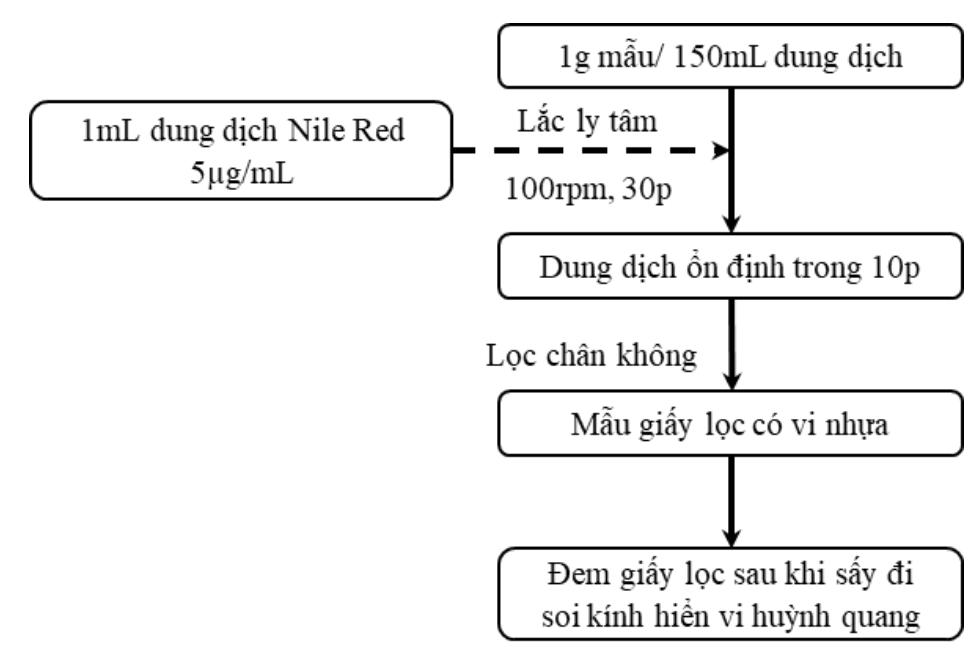

Hình 1. Quy trình chuẩn bị mẫu

Quy trình chuẩn bị $150 \mathrm{~mL}$ dung dịch mẫu nhuộm được điều chỉnh theo nghiên cứu của E. K. Fischer, 2016 [16], mô tả chi tiết ở hình 1. Cân $1 \mathrm{~g}$ mẫu (mẫu nhựa chuẩn/mẫu sản phẩm chăm sóc cá nhân) đã được chuẩn bị từ trước và hòa tan trong bình trung tính có chứa $150 \mathrm{ml}$ nước sôi. Sau đó, hỗn hợp được khuấy bằng que thủy tinh cho đến khi hòa tan hoàn toàn. Hút $1 \mathrm{~mL}$ dung dịch Nile Red $5 \mu \mathrm{g} / \mathrm{mL}$ cho vào erlen $250 \mathrm{~mL}$ đang chứa mẫu. Lắc ly tâm bình erlen ở tốc độ 100 vòng/phút trong 30 phút. Sau đó để dung dịch ổn định trong 10 phút. Lọc chân không dung dịch mẫu bằng giấy lọc $\mathrm{GE}$ Whatman Cellulose Nitrate filter, lỗ lọc $0.45 \mu \mathrm{m}$. Sau khi lọc cho $50 \mathrm{ml}$ nước cất để hòa tan

thêm dung dịch và làm sạch các hạt.

Xác định vi nhựa có trong mẫu: Soi mẫu đã nhuộm bằng kính hiển vi huỳnh quang Olympus BX53 độ phóng đại $40 \mathrm{X}$ với ba bước sóng bao gồm DAPI $(430-470 \mathrm{~nm})$, FITC $(515-560 \mathrm{~nm})$ và SPO ( 650 - 670 $\mathrm{nm}$ ). Hạt nhựa được nhuộm huỳnh quang sẽ phát sáng hơn so với nền. Ghi nhận kết quả bằng cách đếm và đo kích thước của các hạt phát sáng trên giấy lọc. Sau đó, chụp ảnh với máy Olympus DP 73 (sử dụng đèn halogen $12 \mathrm{~V} / 100 \mathrm{~W})$. Hình ảnh sau khi chụp sẽ được xử lý bằng Image $\mathrm{J}$ để xác định xác định được kích thước và mật độ của vi nhựa có trong sản phẩm. Số lượng hạt vi nhựa trên mẫu giấy lọc được tính theo công thức (1). Kết quả báo cáo là trung bình cộng của ba lần thí nghiệm.

$$
N_{M P}=\frac{\sum_{1}^{5} N_{n} \times S_{\text {filter }}}{5 \times S_{1}}
$$

Trong đó, $\mathrm{N}_{\mathrm{MP}}$ : Tổng số vi nhựa trên giấy lọc; $\mathrm{N}_{\mathrm{n}}$ : Tổng số vi nhựa đếm được trên ô quan sát (từ 1 đến 5); $\mathrm{S}_{1}$ : Diện tích của 1 ô quan sát $\left(\mathrm{mm}^{2}\right)$ và $S_{\text {filter: }}$ Diện tích giấy lọc $\left(\mathrm{mm}^{2}\right)$

\subsection{Phương pháp điều tra khảo sát đối với người tiêu dùng}

Song song với việc thực hiện phân tích, một bảng câu hỏi khảo sát sự hiểu biết sự hiện diện của vi nhựa có trong các sản phẩm chăm sóc cá nhân được gửi đến người tiêu dùng trong độ tuổi 15 đến 50 tại quận Gò Vấp, Thành phố Hồ Chí Minh. Kết quả sau khi thu thập được tổng hợp và đưa ra nhận xét. Bảng câu hỏi khảo sát được gửi đến người tiêu dùng bao gồm 13 câu hỏi. Trong đó, 5 câu hỏi liên quan đến thông tin cá nhân bao gồm tuổi, nghề nghiệp và tần suất sử dụng cũng như yếu tố chọn lựa KĐR cũng như các sản phẩm MPT; 4 câu hỏi liên quan đến sự hiểu biết về vi nhựa cũng như sự tồn tại của vi nhựa trong các sản phẩm chăm sóc cá nhân; và 4 câu hỏi liên quan đến thái độ xử lý của người phỏng vấn đối với các sản phẩm chứa vi nhựa cũng như ý thức tìm hiểu thêm về vi nhựa cũng như các tác động môi trường và sức khoẻ của nó.

\section{KẾT QUẢ VÀ THẢO LUẬN}

\subsection{Các điều kiện tối ưu của nhuộm huỳnh quang trên mẫu nhựa chuẩn}

Trong nghiên cứu này, xác định các điều kiện nhuộm huỳnh quang trên mẫu nhựa chuẩn bao gồm nồng độ dung dịch Nile Red (pha loãng bằng dung môi acenton), thể tích dung dịch Nile Red sử dụng, các loại giấy lọc khác nhau sử dụng lọc mẫu và bước sóng phát xạ. 
Dung dịch Nile Red gốc (1mg/mL) được pha loãng 100, 200 và 300 lần với aceton để tạo ra các dung dịch trung gian với nồng độ tương ứng lần lượt là 10,5 và $3.3 \mu \mathrm{g} / \mathrm{mL}$. Các mẫu nhựa được nhuộm với dung dịch trung gian và cho kết qủa như hình 2 . Khoảng nồng độ pha loãng từ 100 đến 300 lần có thể quan sát được có mẫu vi nhựa, nhưng ở cùng thời gian phơi sáng $(0,62 \mathrm{~s})$ nồng độ pha loãng 100 lần thì quá cao làm cho nền giấy lọc phát sáng chói khó có thể quan sát được vi nhựa. Còn đối với nồng độ pha loãng 300 lần thì màu nền phát tối. Nền giấy lọc phát sáng tối ưu phù hợp giữa nền và vi nhựa thì nồng độ pha loãng nằm ở 200 lần tương ứng nồng độ $5 \mu \mathrm{g} / \mathrm{mL}$.

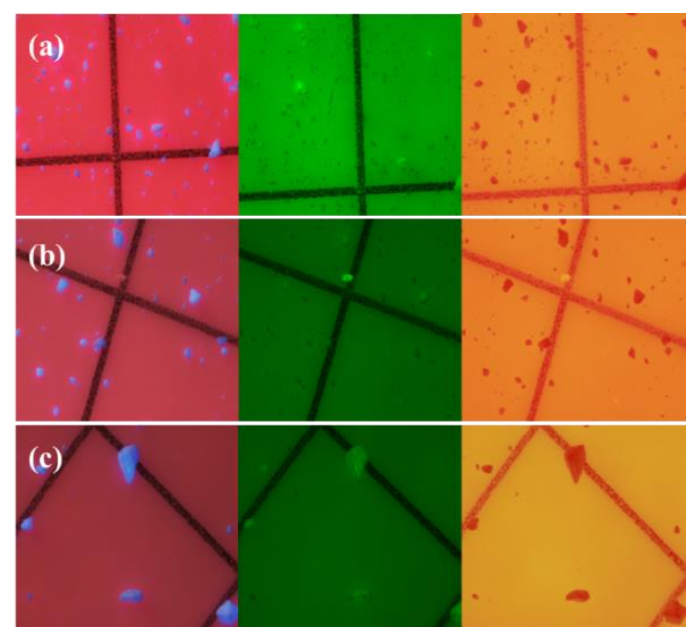

Hình 2: Hình ảnh mẫu nhựa PET dưới kính hiển vi huỳnh quang khi nhuộm trong dung dịch Nile Red được pha loãng 100 (a), 200 (b) và 300 lần (c)

Hình 3 cho thấy, ở cùng thời gian phơi sáng liều lượng thuốc nhuộm $0,5 \mathrm{ml}$ thì khả năng phát sáng của màu nền và hạt nhựa không cao. Đối với liều lượng từ $2 \mathrm{ml}$ đến $3 \mathrm{ml}$ khả năng phát sáng của màu nền quá cao khó quan sát được những hạt vi nhựa trong mẫu nhựa. Liều lượng thuốc nhuộm tối ưu để sử dụng trong mẫu là $1 \mathrm{~mL}$.
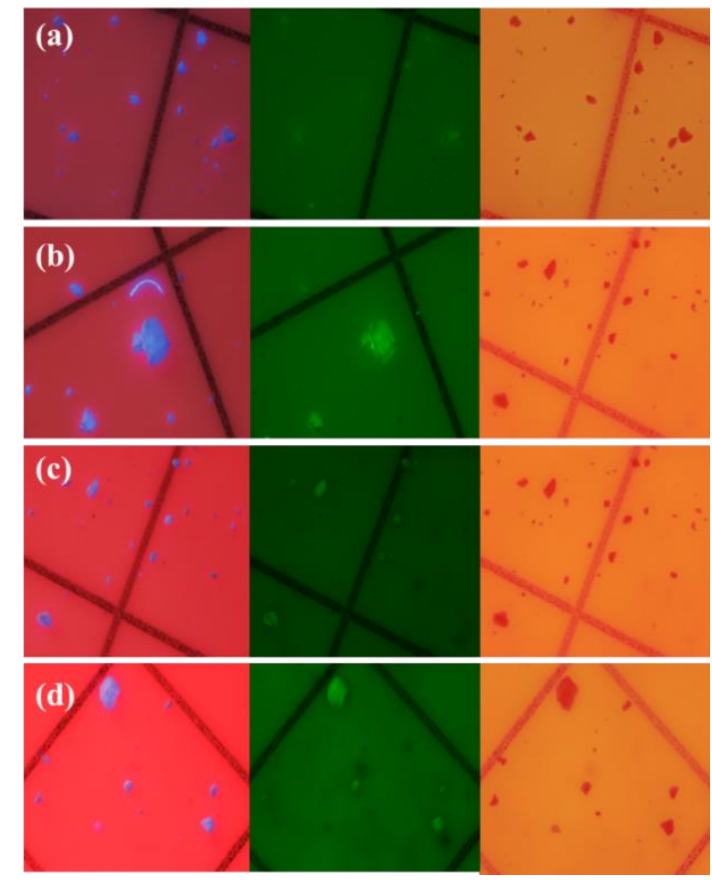

Hình 3: Hình ảnh mẫu nhựa PET dưới kính hiển vi huỳnh quang được nhuộm với dung dịch Nile Red $(5 \mu \mathrm{g} / \mathrm{mL})$ với các thể tích khác nhau: $0,5 \mathrm{~mL}(\mathrm{a}), 1 \mathrm{~mL}(\mathrm{~b}), 2 \mathrm{~mL}$ (c) và $3 \mathrm{~mL}$ (d) 


\section{NGHIÊN CUUU ĐINH LƯƠNG VI NHƯA TRONG CÁC SẢN PHẨM CHĂM SÓC CÁ NHÂN BẰNG PHƯỚNG PHÁP NHUỘM NILE RED VÀ KHẢO SÁT SỬ HIẾU BIÊT CỦA NGƯỜI TIÊU DÙNG VỀ TỒN TẠI VI NHỰA TRONG CÁC SẢN PHẨM NÀY}

Để so sánh ảnh hưởng của dung dịch nhuộm lên các loại giấy lọc, ba loại giấy lọc được sử dụng để chứa các mẫu nhựa bao gồm Whatman Filter Papers (No.1003 - 110), Whatman Cellulose Nitrate và Whatman Cellulose Ester. Dựa vào hình 4 , cùng loại mẫu nhựa PET được sử dụng để làm mẫu đối với giấy lọc Whatman Filter Papers (No.1003 - 110) hạt nhựa phát màu đỏ cam đối với 3 bước sóng khó có thể phân loại nhưng đối với 2 loại giấy lọc Whatman Cellulose Nitrate và Whatman Cellulose Ester thì mẫu nhựa được dùng trong thí nghiệm phát màu xanh nước biển. Tuy nhiên, giấy lọc Cellulose Ester lại tan nhanh trong dung môi acetone hơn Cellulose Nitrat, điều này gây khó khăn cho việc nhận diện vi nhựa trên giấy lọc. Do đó, Whatman Cellulose Nitrate được sử dụng cho các thí nghiệm tiếp theo.

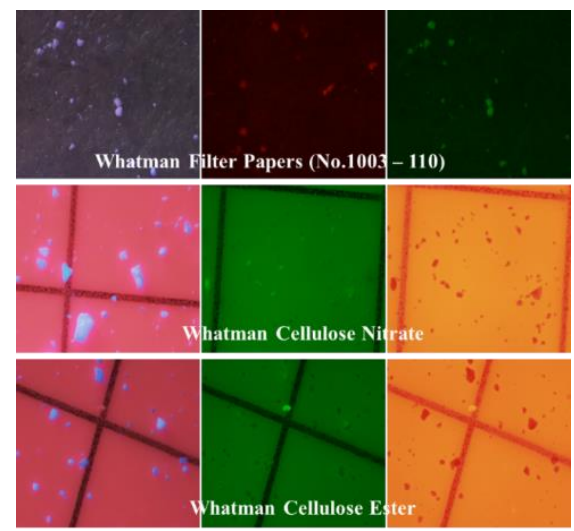

Hình 4: Mẫu nhựa PET dưới kính hiển vi huỳnh quang sau khi nhuộm dung dịch Nile Red trên các giấy lọc khác nhau

Kết quả nghiên cứu cho thấy hạt nhựa được nhuộm huỳnh quang sẽ phát sáng hơn so với nền. Mỗi loại vi nhựa sẽ phát sáng ở các bước sóng khác nhau. Cụ thể ở ba bước sóng: DAPI (430 - $470 \mathrm{~nm})$ nhựa PET bắt màu thuốc nhuộm và phát màu xanh nước biển đậm; FITC $(515-560 \mathrm{~nm})$ - nhựa LDPE, HDPE, PP bắt màu thuốc nhuộm và phát màu xanh lá. Tại bước sóng $\mathrm{SPO}(650-670 \mathrm{~nm})$ các mẫu nhựa sử dụng không bắt màu thuốc nhuộm và phát màu (hình 5 ). Sự khác biệt trong sử dụng bước sóng và phát xạ của Nile Red trong phương pháp nhuộm lipid ở các mẫu sinh học và vi nhựa đã được báo cáo tùy thuộc vào độ phân cực của dung môi, lipid và các điều kiện nhuộm màu. Sự phát huỳnh quang chuyển từ màu đỏ sang màu xanh lục khi tính kỵ nước của dung môi tăng và mục tiêu là nhuộm lipid [17], [18]. Do bề mặt nhựa cũng có đặc tính kỵ nước tự nhiên [19], [20] nên cho kết quả dưới kính hiển vi huỳnh quang khác nhau tuỳ theo bước sóng phát xạ.

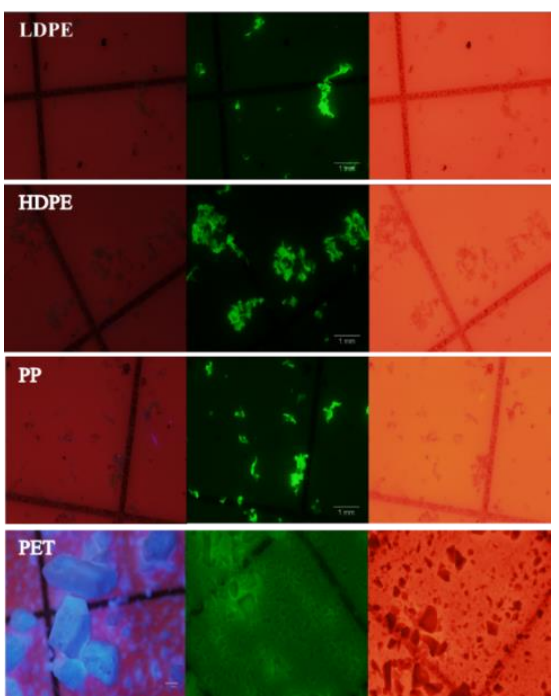

Hình 5: Hình ảnh các mẫu nhựa dưới kính hiển vi huỳnh quang tại các bước sóng DAPI 430 - 470 nm (trái), FITC 515 - 560 nm (giữa) và SPO 650 - $670 \mathrm{~nm}$ (phải) 


\subsection{Kiểm nghiệm sự hiện diện của vi nhựa có trong các sản phẩm chăm sóc cá nhân}

Dựa trên các điều kiện nhuộm Nile Red tối ưu, các mẫu MPT và KĐR được tiến hành nhuộm và soi dưới kính hiển vi huỳnh quang. Hầu hết các mẫu vi nhựa trong các mẫu KĐR và MPT được bắt màu thuốc nhuộm Nile Red phát màu xanh lá nằm trong nhóm bước sóng FITC $(515-560 \mathrm{~nm})$ giống phát xạ của nhóm nhựa LDPE, HDPE và PE và một số thuộc nhóm bước sóng DAPI $(430$ - 470nm) giống phát xạ của nhựa $\mathrm{PP}, \mathrm{PET}$ bắt màu thuốc nhuộm và phát màu xanh nước biển đậm. Kết quả nghiên cứu cho thấy sự hiện diện của vi nhựa trong các mẫu thu thập được trình bày trong hình 6 và bảng 1 .

Kết quả thí nghiệm cho thấy nhiều loại MPT và KĐR chứa hạt vi nhựa. Các hạt nhựa chủ yếu phát màu xanh lục và xanh dương. Trong đó, 2 mẫu MPT đều chứa hạt vi nhựa với $100 \%$ số lượng có dạng hạt tròn với 2710 và 771 hạt/g lần lượt đối với mẫu $\mathrm{C} 1$ và $C 2$. So sánh với nghiên cứu của $S$. M. Praveena và cộng sụ (2018) (11776 - 36636 hạt/g) cho thấy lượng vi nhựa trong các sản phẩm MPT thu được thấp hơn nhiều [21].

Trong các mẫu KĐR dành cho trẻ em trong và ngoài nước, mẫu KĐR R2 chứa số lượng hạt vi nhựa nhiều nhất 12.427 hạt/g KĐR. R2 là một mẫu KĐR có xuất xứ nước ngoài dành cho trẻ em. Các mẫu KĐR dành cho trẻ em còn lại có rất ít (R12, R19, sản phẩm nội địa) hoặc không phát hiện vi nhựa có trong sản phẩm (R15, sản phẩm ngoại nhập). Đối với các mẫu KĐR cho người lớn, trong 10 mẫu có chức năng tẩy trắng phát hiện 9 mẫu có tồn tại vi nhựa bao gồm các nhãn hiệu trong và ngoài nước. KĐR ngoại nhập có chức năng tẩy trắng chứa lượng vi nhựa cao nhất là $\mathrm{R} 1$ với 17.582 hạt/1g sản phẩm. Các loại tiếp theo là $\mathrm{R} 9$ có 5.780 hạt, $\mathrm{R} 4$ có 4.046 hạt, R3 có 1.734 vi nhựa dạng sợi, R17 có 650 vi nhựa dạng sợi trong mỗi 1g mẫu và $\mathrm{R} 14$ hầu như không phát hiện tồn tại vi nhựa. KĐR có tẩy trắng sản xuất trong nước bao hồm R6, R18, R20 và $R 11$ với lượng vi nhựa lần lượt là $3.294,5.471,5.781$ và 3.468 hạt/sợi trên $1 \mathrm{~g}$ mẫu.

Ngược lại, đối với các mẫu KĐR không có chức năng tây trắng, lượng vi nhựa phát hiện trong các mẫu ít hơn nhiều so với loại có chứa chức năng tẩy trắng. Cụ thể, các mẫu $\mathrm{R} 7$ và $\mathrm{R} 8$ là sản phẩm ngoại nhập chỉ chứa tương ứng là 2.312 và 1.734 hạt/1g mẫu. Đặc biệt, các mẫu KĐR có xuất xứ từ châu Âu như R10, R14 và R16 hoàn toàn không phát hiện sự hiện diện của vi nhựa. Bên cạnh đó, một số mẫu KĐR thảo dược nội địa mà không có chức năng tẩy trắng như R5 và R21 cũng không phát hiện vi nhựa tồn tại. Cũng vậy, một mẫu nội địa khác R13 cũng phát hiện được lượng vi nhựa là 1.734 hạt trong $1 \mathrm{~g}$ mẫu thí nghiệm. Riêng đối với các mẫu KĐR được lấy từ các khách sạn không thấy hiện diện của các hạt vi nhựa (bảng 1 ). Điều này cho thấy khả năng liên hệ giữa tính năng làm trắng của các loại KĐR có liên quan đến hiện diện của vi nhựa có trong sản phẩm. Microplastic đã được thêm vào KĐR để tăng tính thẩm mỹ và hỗ trợ trong làm sạch và chức năng như một chất làm mịn. Tuy nhiên, lượng hạt vi nhựa trong các sản phẩm KĐR ở nghiên cứu này vẫn còn rất thấp so với nghiên cứu của $\mathrm{S}$. M. Praveena và cộng sự với lượng hạt dao động từ 27.688 - 48.992 hạt/g mẫu [21].

Hình dạng, kích thước của hạt vi nhựa trong các mẫu không đều nhau. Kết quả này cũng tương tự trong các nghiên cứu khác [22], [4]. Các hạt trong sản phẩm tẩy tế bào chết và kem đánh răng quan sát được có phạm vi kích thước rộng. Kích thước hạt tẩy tế bào chết dao động từ $<0,3 \mathrm{~mm}$ đến $<5 \mathrm{~mm}$ trong khi kích thước hạt đối với kem đánh răng dao động từ $0,3 \mathrm{~mm}$ đến $0,1 \mathrm{~mm}$. Kích thước hạt nhựa trong nghiên cứu này thấp hơn hạt kích thước hạt của nghiên cứu khác. Theo nghiên cứu của $\mathrm{P}$. K. Cheung và L. Fok, kích thước hạt vi nhựa nằm trong khoảng từ $24 \mu \mathrm{m}$ đến $800 \mu \mathrm{m}$ [22]. L. S. Fendall và M. A. Sewell báo cáo kích thước của hạt nhựa trong khoảng từ 4,1 đến $1.240 \mu \mathrm{m}$ [4] và theo $\mathrm{I}$. E. Napper và cộng sụ đường kính trung bình là $163,82 \mu \mathrm{m}$ [12]. Sự khác biệt này có thể là do các phương pháp khác nhau được sử dụng trong nhận dạng microplastic. Ngoài ra, vi nhựa có kích thước đường kính lên tới $500 \mu \mathrm{m}$ trong các sản phẩm chăm sóc cá nhân và mỹ phẩm như sữa rửa mặt, tẩy tế bào chết và thay thế cho các chất tẩy tế bào chết tự nhiên. Hơn nữa, thành phần nhựa tương tự của LDPE đã được phát hiện trong các sản phẩm tẩy tế bào chết trên da mặt [22], [12], [23], [24], [25]. Kết quả nghiên cứu đã nhấn mạnh một điều rằng thực tế sử dụng liên tục các sản phẩm chăm sóc cá nhân và mỹ phẩm hàng ngày có thể phát thải một lượng lớn vi nhựa ra môi trường. Mặc dù phương pháp sử dụng nhuộm huỳnh quang Nile-Red này không xác định được thông tin cấu trúc hóa học của các hạt, nhưng cho phép đánh giá nhanh chóng số lượng lớn mẫu, dễ dàng thực hiện, cho kết quả nhanh và ít tốn kém chi phí. 
204 NGHIÊN CỨU ĐỊNH LƯỢNG VI NHỬA TRONG CÁC SẢN PHẨM CHĂM SÓC CÁ NHÂN BẰNG PHƯƠNG PHÁP NHUỘM NILE RED VÀ KHẢO SÁT SỰ HIỂU BIÊTT CỦA NGƯỜI TIÊU DÙNG VỂ TÔN TẠI VI NHỰA TRONG CÁC SẢN PHẨM NÀY
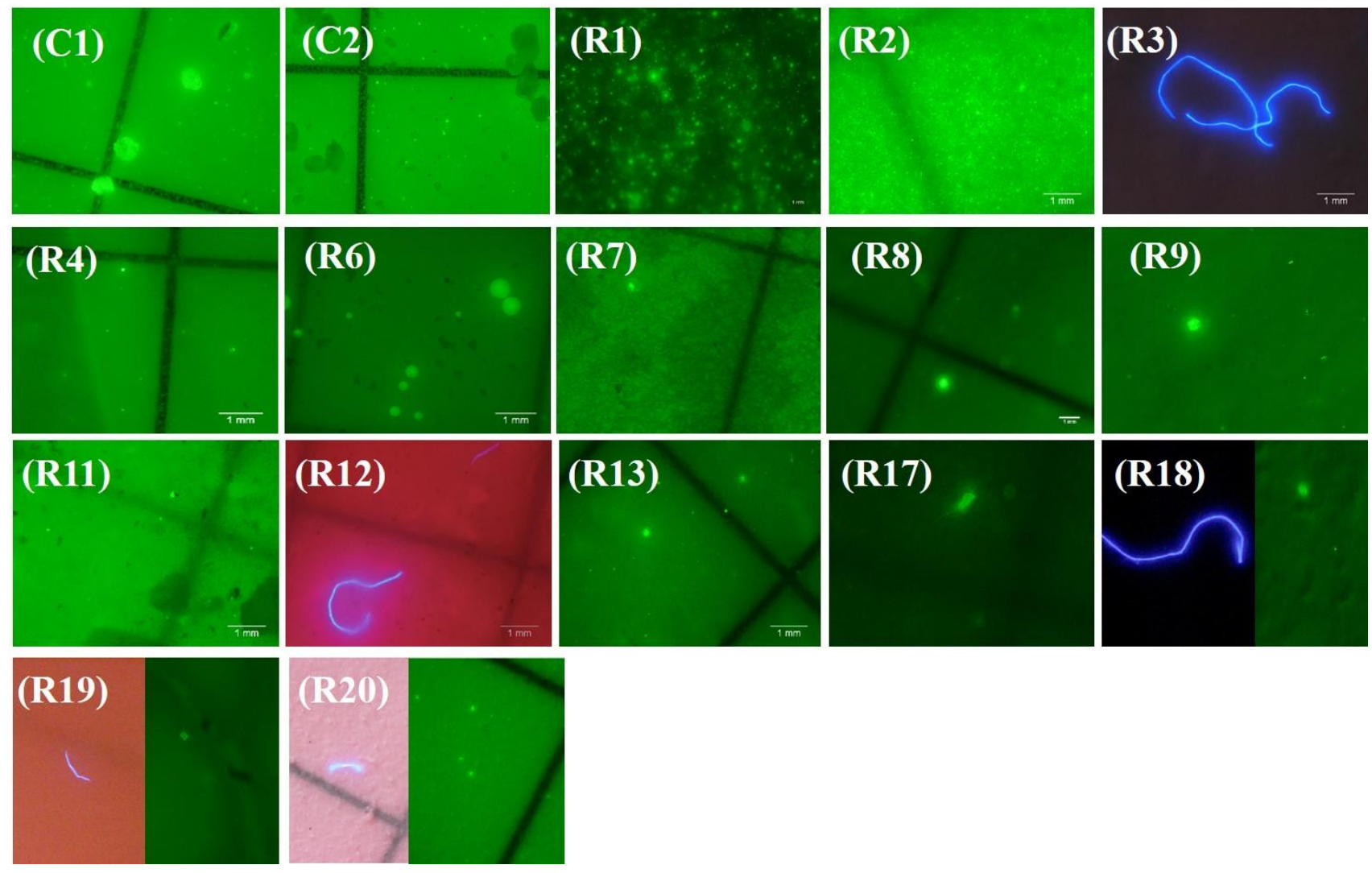

Hình 6: Hình ảnh vi nhựa tồn tại trong các mẫu mỹ phẩm tẩy tế bào chết $(\mathrm{C} 1, \mathrm{C} 2)$ và các mẫu kem đánh răng $(\mathrm{R})$

Bảng 1: Kết quả xác định vi nhựa trong các mẫu sản phẩm chăm sóc cá nhân đã thu thập

\begin{tabular}{|c|c|c|c|c|c|c|c|}
\hline \multirow{2}{*}{$\begin{array}{c}\text { Loại } \\
\text { sản phẩm }\end{array}$} & \multirow{2}{*}{ Tên } & \multicolumn{2}{|c|}{ Hình dạng } & \multirow{2}{*}{$\begin{array}{l}\text { Lượng vi nhựa } \\
\text { trên } 1 \mathrm{~g}\end{array}$} & \multicolumn{3}{|c|}{ Kích thước (lượng vi nhựa trên 1 g) } \\
\hline & & Tròn & Sợi & & $<0,3 \mathrm{~mm}$ & $0,3 \mathrm{~mm}-1 \mathrm{~mm}$ & $1 \mathrm{~mm}-5 \mathrm{~mm}$ \\
\hline \multirow{2}{*}{$\begin{array}{l}\text { Tẩy tế bào } \\
\text { chết (Scrub) }\end{array}$} & $\mathrm{C} 1$ & $\mathrm{x}$ & & $2.710 \pm 327$ & $2.021 \pm 138$ & $654 \pm 20$ & $35 \pm 12$ \\
\hline & $\mathrm{C} 2$ & $\mathrm{x}$ & & $771 \pm 112$ & $470 \pm 27$ & $296 \pm 7$ & 5 \\
\hline \multirow{17}{*}{$\begin{array}{l}\text { Kem đánh } \\
\text { răng }\end{array}$} & R1 & $\mathrm{x}$ & & $17.582 \pm 1.227$ & $11.898 \pm 837$ & $3.203 \pm 110$ & $2.482 \pm 114$ \\
\hline & R2 (TE) & $\mathrm{x}$ & & $12.427 \pm 373$ & $3.468 \pm 15$ & $6.069 \pm 127$ & $2.890 \pm 111$ \\
\hline & R3 & $\mathrm{x}$ & $x$ & $1.734 \pm 111$ & & & $1.734 \pm 111$ \\
\hline & $\mathrm{R} 4$ & $\mathrm{x}$ & & $4.046 \pm 1.445$ & & $2.312 \pm 235$ & $1.734 \pm 156$ \\
\hline & R5 & & & KPH & & & \\
\hline & R6 & $\mathrm{x}$ & $\mathrm{x}$ & $3.294 \pm 578$ & & $2.138 \pm 137$ & $1.156 \pm 47$ \\
\hline & R7 & $\mathrm{x}$ & & $2.312 \pm 156$ & & $1.156 \pm 68$ & $1.156 \pm 68$ \\
\hline & $\mathrm{R} 8$ & $\mathrm{x}$ & & $1.734 \pm 34$ & & $1.734 \pm 34$ & \\
\hline & R9 & $\mathrm{x}$ & & $5.780 \pm 347$ & & $5.780 \pm 347$ & \\
\hline & R10 & & & KPH & & & \\
\hline & R11 & $\mathrm{x}$ & & $3.468 \pm 134$ & & $3.468 \pm 134$ & \\
\hline & R12 (TE) & & $x$ & 2 & & 1 & 1 \\
\hline & R13 & $\mathrm{x}$ & & $1.734 \pm 47$ & & & $1.734 \pm 47$ \\
\hline & R14 & & & KPH & & & \\
\hline & R15 (TE) & & & KPH & & & \\
\hline & R16 & & & KPH & & & \\
\hline & R17 & $\mathrm{x}$ & & $650 \pm 27$ & & & $650 \pm 27$ \\
\hline
\end{tabular}



TỒN TẠI VI NHỰA TRONG CÁC SẢN PHẨM NÀY

\begin{tabular}{|l|c|c|c|r|r|r|r|}
\hline & $\mathrm{R} 18$ & $\mathrm{x}$ & $\mathrm{x}$ & $5.471 \pm 1.206$ & & $1.445 \pm 527$ & $4026 \pm 539$ \\
\cline { 2 - 8 } & $\mathrm{R} 19(\mathrm{TE})$ & $\mathrm{x}$ & $\mathrm{x}$ & $13 \pm 7$ & 3 & 9 & 1 \\
\cline { 2 - 8 } & $\mathrm{R} 20$ & $\mathrm{x}$ & $\mathrm{x}$ & $5.781 \pm 827$ & & $5.780 \pm 827$ & 1 \\
\cline { 2 - 8 } & $\mathrm{R} 21$ & & & KPH & & & \\
\cline { 2 - 7 } & $\mathrm{R} 22(\mathrm{KS})$ & & & KPH & & & \\
\cline { 2 - 7 } & $\mathrm{R} 23(\mathrm{KS})$ & & & KPH & & & \\
\cline { 2 - 7 } & $\mathrm{R} 24(\mathrm{KS})$ & & & KPH & & & \\
\hline
\end{tabular}

Ký hiệu: TE: KĐR trẻ em, KS: KĐR khách sạn, KPH: không phát hiện

\subsection{Khảo sát sự hiểu biết của người tiêu dùng về tồn tại vi nhựa trong các sản phẩm chăm sóc cá nhân}

Tổng phiếu khảo sát thu thập được là 110 phiếu. Người tiêu dùng tham gia khảo sát ở độ tuổi 20 - 30 là nhiều nhất $(85,3 \%)$, tiếp đển là ở độ tuổi 30 - 40 tuổi $(8,3 \%)$ và $15-20$ tuổi $(5,5 \%)$ và trên 40 tuổi $(0,9$ \%). Như vậy, khoảng độ tuổi khảo sát chủ yếu rơi vào độ tuổi ổn định và cận lão hóa, nhóm tuổi quyết định sản phẩm tiêu dùng trong gia đình. Đây cũng là nhóm tuổi tiếp xúc nhiều với kiến thức phổ thông và trao đổi thông tin, phản ánh được thị hiếu sản phẩm và sự quan tâm của người tiêu dùng về vi nhựa. Bên cạnh đó, theo khảo sát về nghề nghiệp thì tỷ lệ công nhân và viên chức (làm việc trong nhà, văn phòng kín) chiếm cao nhất với $62,4 \%$ trên tổng số phiểu khảo sát, tiếp đến là $33 \%$ học sinh, sinh viên và phần nhỏ còn lại là công nhân, lao động ngoài trời và nội trợ. Với tỷ lệ nghề nghiệp như trên thì trong đánh giá này rất hữu ích vì nhu cầu chi tiêu cho các sản phẩm chăm sóc cá nhân sẽ ưu tiên chất lượng sản phẩm hơn là giá cả. Lý do là thu nhập bình quân đầu người của nhóm đối tượng khảo sát có tỷ lệ cao nhất (công nhân viên chức) cao hơn các nhóm còn lại.

Tỉ lệ người khảo sát đánh răng ít nhất 1 lần/ ngày chiếm 98,2\%. Thói quen đánh răng ít nhất 2 lần một ngày đã được phổ biến trong xã hội hiện nay, từ các phương tiện thuyền thông đại chúng và trong lối sống sinh hoạt. KĐR trở thành nhu cầu sử dụng mỗi ngày, có lượng tiêu thụ lớn trong cộng đồng dân cư. Ngược lại, các sản phẩm MPT có tần suất sử dụng thấp hơn nhiều với $51,8 \%$ sử dụng với tần suất $1-2$ lần/tuần, tiếp đến $40 \%$ sử dụng với tần suất 1-2 lần/ngày và còn lại sử dụng với tần suất $3-5$ lần/tuần.

Kết quả khảo sát cho thấy hơn $70 \%$ người khảo sát chưa từng biết đến vi nhựa và có nghe nói đến nhưng không quan tâm. Trong khi đó tỉ lệ người biết rõ về vi nhựa và có quan tâm chỉ chiếm 28,5\% (Hình $7 \mathrm{a}$ ). Tương đồng với kết quả trên, sự hiểu biết của người tiêu dùng về thành phần vi nhựa trong mỹ phẩm cũng như các sản phẩm chăm sóc cá nhân cũng khá thấp. Đa số người tiêu dùng không biết hoặc không quan tâm về thành phần vi nhựa có trong sản phẩm (Hình $7 \mathrm{~b}$ ). Do đó, $85-90 \%$ số người được phỏng vấn không biết đến lý do sử dụng vi nhựa trong KĐR cũng như các MPT nhằm mục đích gì cũng như tác hại của nó. Như vậy, mặc dù hiện trạng ô nhiễm nhựa đang bùng phát nhưng ô nhiễm vi nhựa chưa nhận được sự quan tâm rộng rãi. Các cầu trả lời của những người được khảo sát quan tâm đến tác dụng của vi nhựa trong sản phẩm chăm sóc cá nhân như: hút chất bẩn sâu dưới lỗ chân lông, tăng ma sát với bề mặt da và răng, loại bỏ bụi và chất nhờn trên da, làm sạch, ... Bên cạnh đó, cũng chính những người này nêu những tác hại của vi nhựa hay khi sử dụng các sản phẩm chăm sóc cá nhân có chứa vi nhựa đó là gây ô nhiễm môi trường nước, sinh vật; gây nhiều bệnh thần kinh và hô hấp; tổn thương não; hay đơn giản là ảnh hưởng đến sức khoẻ và môi trường. 
(a)

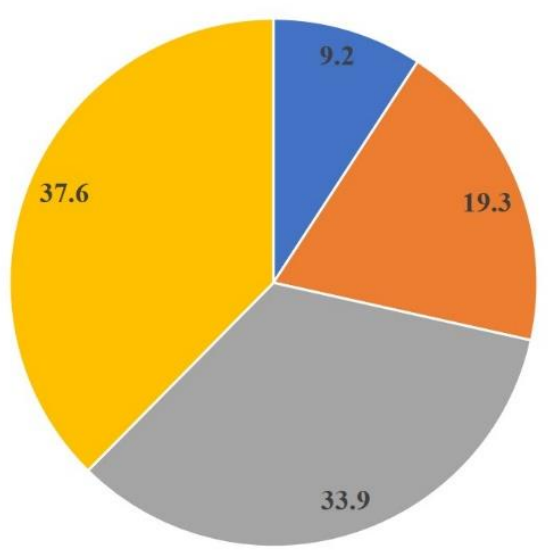

- Hiểu biết rõ về vi nhựa

" Có nghe nói đến và rất quan tâm

- Có nghe nói đến nhưng không quan tâm

= Chưa từng nghe (b)

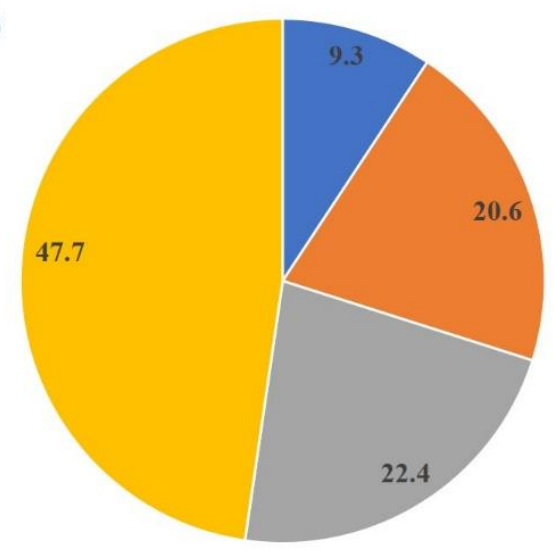

- Biết rất rõ

- Có nghe nói đến và muốn tìm hiễu

- Có nghe nói đến nhưng không quan tâm

= Chưa từng nghe

Hình 7: Khảo sát mức độ hiểu biết và quan tâm của người tiêu dùng về vi nhựa trong môi trường (a) và trong các sản phẩm chăm sóc cá nhân (b)

Tuy nhiên, khi được hỏi có nên sử dụng tiếp các sản phẩm chứa thành phần vi nhựa gây hại cho sức khoẻ không thì $35.8 \%$ số người khảo sát quyết định tạm dừng sử dụng và hơn $48 \%$ số người khảo sát sẵn sàng khuyến cáo cho người thân và bạn bè về sản phẩm không an toàn (Hình $8 \mathrm{a}$ ). Một số người khác vẫn cho rằng sẽ tiếp tục sử dụng các sản phẩm này và có phần tiết chế hơn.

Tổ chức môi trường Liên hiệp quốc (UNEP) đưa ra lời kêu gọi về việc cấm sử dụng hạt vi nhựa trong mỹ phẩm nhằm bảo vệ môi trường cũng như sức khỏe của con người trong tương lai. Mỹ, Canada và một số nước châu Âu đã yêu cầu các công ty hóa mỹ phẩm ngừng ngay việc sử dụng các loại hạt vi nhựa trong sản xuất mỹ phẩm. Theo đó, $97,1 \%$ số người được khảo sát cho rằng Việt Nam cũng cần có luật và chế tài quy định loại bỏ thành phần vi nhựa trong các sản phẩm chăm sóc cá nhân (Hình 8c). Bên cạnh đó, có đến 96,2 \% người tiêu dùng mong muốn các nhà sản xuất thay thế và loại bỏ hoàn toàn vi nhựa trong các sản phẩm này (Hình $8 \mathrm{~b}$ ). Nguời tiêu dùng vẫn có xu hướng sử dụng các chất thay thế có nguồn gốc từ thiên nhiên $(65,1 \%)$. Họ mong muốn thay thế thành phần sẵn có nhưng chất lượng vẫn được đảm bảo.

Một mặt khác, khảo sát này một phần giúp cho người tiêu dùng nhận biết về thành phần vi nhựa có trong các sản phẩm chăm sóc cá nhân như KĐR, MPT. Điều này cũng giúp tăng cường nhận thức của người tiêu dùng đối với tác hại của vi nhựa đến sức khoẻ và môi trường sống. Như mô tả ở Hình $8 \mathrm{~d}$, đa số người tiêu dùng mong muốn tìm hiểu thêm về vi nhựa và tác hại của nó $(50,9 \%)$ và sẽ xem xét thành phẩn có trong mỹ phẩm trước khi mua nhất là thành phần liên quan đến vi nhựa $(27,4 \%)$. Bên cạnh đó, tỉ lệ người tham gia khảo sát sẽ khuyến cáo cho bạn bè và người thân biết tác hại của vi nhựa có trong mỹ phẩm chiếm $16 \%$. Tỉ lệ người tiêu dùng tiếp tục sử dụng sản phẩm có chứa vi nhựa khi đã biết tác hại về sức khỏe gần như không có. Điều này chứng minh rằng việc nghiên cứu, đánh giá về vi nhựa có trong các sản phẩm chăm sóc cá nhân và tác hại của chúng đến sức khỏe người tiêu dùng là cần thiết. Nghiên cứu góp phần nâng cao nhận thức của người tiêu dùng, loại bỏ các sản phẩm chứa vi nhựa, giảm thiểu nguồn phát thải và có thể áp dụng các biện pháp phòng ngừa rộng rãi. Từ đó có thể giúp thay đổi thị hiếu của người tiêu dùng và khuyến khích các nhà sản xuất không sử dụng thành phần vi nhựa trong mỹ phẩm. 


\section{TỒN TẠI VI NHỰA TRONG CÁC SẢN PHẨM NÀY}

(a)

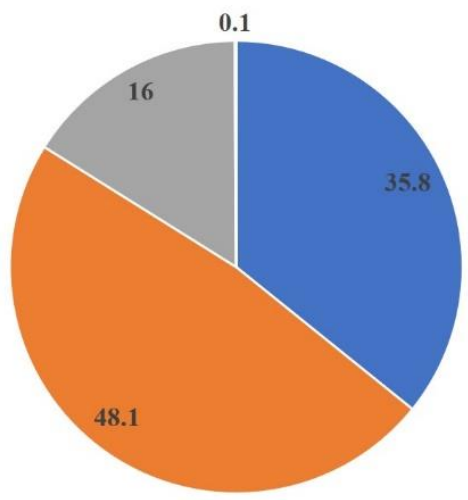

- Ngưng sử dụng

• Ngưng sử dụng và khuyến cáo cho người khác

• Vẫn tiếp tục sử dụng nhưng hạn chế hơn

- Tiếp tục sử dụng như bình thường

(c)

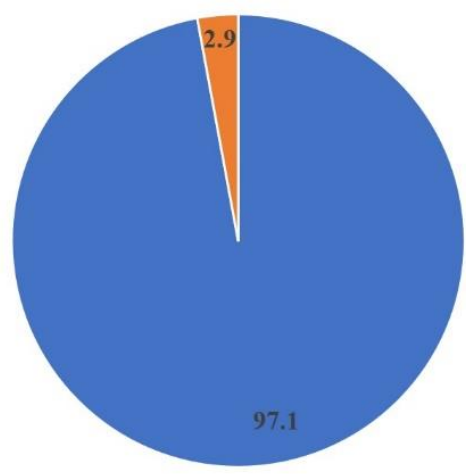

- Nên có luật và chế tài cấm sử dụng vi nhựa trong các sản phẩm chăm sóc cá nhân

* Không cần thiết (b)

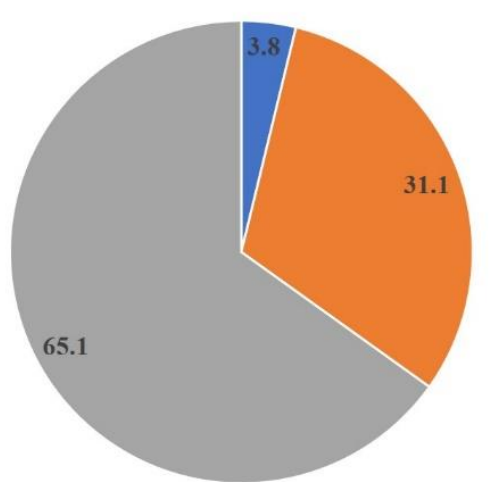

• Giữ nguyên và vẫn tiếp tục lưu hành trên thị trường

• Loại bỏ vi nhựa trong sản phẩm

- Cải tiến bằng cách thay thế các thành phần tự nhiên có chức năng tương tự như vi nhựa

(d)

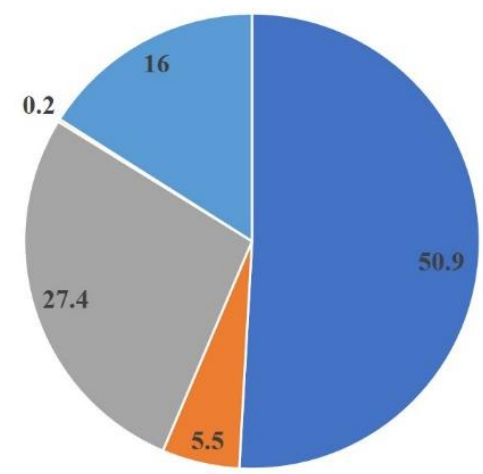

" Mong muốn tìm hiểu thêm

" Không quan tâm

- Xem xét rõ các thành phần trước khi mua

- Vẫn sử dụng các sản phẩm đã và đang dùng

• Khuyến cáo hoặc nói cho người khác về vi nhựa khi mua sản phẩm

Hình 8: Thái độ và nhận thức của người tiêu dùng về việc sử dụng các sản phẩm chăm sóc cá nhân chứa vi nhựa: (a) tiếp tục sử dụng sản phẩm khi phát hiện có vi nhựa, (b) mong muốn đối với nhà sản xuất các sản phẩm KĐR và sản phẩm chăm sóc cá nhân, (c) yêu cầu về xây dựng luật đối với sử dụng vi nhựa trong các sản phẩm chăm sóc cá nhân và $(\mathrm{d})$ mong muốn tìm hiều về sản phẩm chứa vi nhựa.

\section{KẾT LUẬN}

Nghiên cứu là báo cáo đầu tiên ở Việt Nam về vi nhựa có trong sản phẩm chăm sóc cá nhân cụ thể là KĐR và $\mathrm{MPT}$ có xuất xứ trong và ngoài nước. Kết quả thí nghiệm cho thấy đa số các loại sản phẩm KĐR và MPT đều chứa hạt nhựa, nhất là sản phẩm KĐR người lớn $\mathrm{R} 1$, và trẻ em $\mathrm{R} 2$ cao đáng kể hơn các sản phẩm khác, lần lượt là 17.582 và 12.427 hạt/g. Nghiên cứu cũng đề xuất được quy trình với các điều kiện tối ưu để đánh giá nhanh sự tồn tại vi nhựa trong các mẫu thu được. Kết quả có thể được sử dụng để làm cơ sở cho các nghiên cứu tiếp theo về ô nhiễm vi nhựa trong môi trường. Qua khảo sát cho thấy, sự hiểu biết của người tiêu dùng được phỏng vấn trong về vi nhựa trong môi trường và trong các sản phẩm chăm sóc cá nhân, chỉ chiếm lần lượt $28,5-29,9 \%$. Tuy nhiên, sau phỏng vấn cho thấy thái độ và nhận thức của người tiêu dùng về việc sử dụng các sản phẩm chăm sóc cá nhân chứa vi nhựa cao hơn nhiều. Có đến $83.9 \%$ số người phỏng vấn sẽ ngưng sử dụng và khuyến cáo cho người khác đối với các sản phẩm chăm sóc cá nhân chứa vi nhựa. Số người mong muốn tìm hiều về vi nhựa đạt đến hơn $50 \%$ và $97 \%$ đồng ý phải có chế tài 
và luật cấm sử dụng vi nhựa trong sản phẩm. Như vậy, nghiên cứu góp phần hỗ trợ, khuyến khích đối với các hành động, thái đội và nhận thức của người tiêu dùng giảm lượng vi nhựa được giải phóng ra môi trường từ các sản phẩm chăm sóc cá nhân và mỹ phẩm.

\section{TÀI LIỆ THAM KHẢO}

[1] G. Erni-cassola, M. I. Gibson, and R. C. Thompson, "Lost, but found with Nile red; a novel method to detect and quantify small microplastics ( $20 \mu \mathrm{m}-1 \mathrm{~mm}$ ) in environmental samples," pp. 1-27, 2017.

[2] M. Sartain, E. Sparks, and C. Wessel, M I C R O P L A S T I C S Sampling and Processing Guidebook. Mississippi State University, 2018.

[3] P. Kershaw, A. Anderson, A. Andrady, and A. Courtney, Sources, fate and effects of microplastics in the marine environment: a global assessment. London, 2015.

[4] L. S. Fendall and M. A. Sewell, "Contributing to marine pollution by washing your face: Microplastics in facial cleansers," Mar. Pollut. Bull., vol. 58, pp. 1225-1228, 2009.

[5] H. A. Leslie, Plastic in Cosmetics. United Nations Environment Programme (UNEP), 2015.

[6] T. Gouin and I. Brunning, "Use of Micro-Plastic Beads in Cosmetic Products in Europe and Their Estimated Emissions to the North Sea Environment," ResearchGate, pp. 1-9, 2015.

[7] M. Eriksen et al., "Microplastic pollution in the surface waters of the Laurentian Great Lakes," Mar. Pollut. Bull., vol. 77, pp. 177-182, 2013.

[8] T. Gouin, N. Roche, R. Lohmann, and G. Hodges, "A Thermodynamic Approach for Assessing the Environmental Exposure of Chemicals Absorbed to Microplastic," ACS Publ., pp. 1466-1472, 2011.

[9] J. Boucher and D. Friot, Primary Microplastics in the Oceans: A Global Evaluation of Sources. IUCN, 2017.

[10] I. E. Napper, A. Bakir, S. J. Rowland, and R. C. Thompson, "Characterisation, quantity and sorptive properties of microplastics extracted from cosmetics," Mar. Pollut. Bull., vol. 99, pp. 178-185, 2015.

[11] M. Eriksen et al., "Plastic Pollution in the World's Oceans More than 5 Trillion Plastic Pieces Weighing over 250, 000 Tons Afloat at Sea," PLoS One, pp. 1-15, 2014.

[12] I. E. Napper, A. Bakir, S. J. Rowland, and R. C. Thompson, "Characterisation, quantity and sorptive properties of microplastics extracted from cosmetics," Mar. Pollut. Bull., pp. 1-7, 2015.

[13] T. Maes, R. Jessop, N. Wellner, K. Haupt, and A. G. Mayes, "A rapid-screening approach to detect and quantify microplastics based on fluorescent tagging with Nile Red," Scientific Reports, vol. 7. 2017.

[14] L. M. Hernandez, N. Yousefi, and N. Tufenkji, "Are There Nanoplastics in Your Personal Care Products?," Environ. Sci. Technol. Lett., vol. 4, no. 7, pp. 280-285, Jul. 2017.

[15] "Nile Red * UltraPure Grade * Assay Protocol with Nile Red," p. 1, 2012.

[16] E. K. Fischer, L. Paglialonga, E. Czech, and M. Tamminga, "Microplastic pollution in lakes and lake shoreline sediments - A case study on Lake Bolsena and Lake Chiusi (central Italy)," Environ. Pollut., vol. 213, pp. 648-657, 2016.

[17] W. J. Shim, Y. K. Song, S. H. Hong, and M. Jang, "Identification and quantification of microplastics using Nile Red staining," Mar. Pollut. Bull., vol. 113, no. 1-2, pp. 469-476, 2016.

[18] J. Hendriks, T. Gensch, L. Hviid, M. A. Van Der Horst, K. J. Hellingwerf, and J. J. Van Thor, "Transient Exposure of Hydrophobic Surface in the Photoactive Yellow Protein Monitored with Nile Red," Biophys. J., 
vol. 82, no. 3, pp. 1632-1643, 2002.

[19] A. Güney, C. Özdilek, M. O. Kangal, and F. Burat, "Flotation characterization of PET and PVC in the presence of different plasticizers," Sep. Purif. Technol., vol. 151, pp. 47-56, 2015.

[20] N. T. Thanh Truc, C.-H. H. Lee, B.-K. K. Lee, and S. R. Mallampati, "Development of hydrophobicity and selective separation of hazardous chlorinated plastics by mild heat treatment after PAC coating and froth flotation," J. Hazard. Mater., vol. 321, pp. 193-202, Jan. 2017.

[21] S. M. Praveena, S. N. M. Shaifuddin, and S. Akizuki, "Exploration of microplastics from personal care and cosmetic products and its estimated emissions to marine environment: An evidence from Malaysia," Mar. Pollut. Bull., vol. 136, no. September, pp. 135-140, 2018.

[22] P. K. Cheung and L. Fok, "Evidence of microbeads from personal care product contaminating the sea," Mar. Pollut. Bull., vol. 109, no. 1, pp. 582-585, Aug. 2016.

[23] P. K. Cheung and L. Fok, "Potential microbead emissions from mainland China ( tonnes microbeads / year ) Plastic EP," Water Res., pp. 1-32, 2017.

[24] A. G. Anderson, J. Grose, S. Pahl, R. C. Thompson, and K. J. Wyles, "Microplastics in personal care products : Exploring perceptions of environmentalists , beauticians and students," MPB, pp. 1-7, 2016.

[25] M. Chang, "Reducing microplastics from facial exfoliating cleansers in wastewater through treatment versus consumer product decisions," MPB, vol. 101, pp. 330-333, 2015.

Ngày nhận bài: 11/05/2020 Ngày chấp nhận đăng: 13/10/2020 